\title{
Selective ablations within the prefrontal cortex of the rat and performance of delayed alternation
}

\author{
JENS KNUD LARSEN and IVAN DIVAC \\ Institute of Neurophysiology, Laboratory of Behavioral Physiology, University of Copenhagen, Denmark
}

\begin{abstract}
Ablations of the pregenual area of the anteromedial prefrontal cortex produced a significantly larger impairment in delayed alternation than did removal of the supragenual area. Both ablations caused significant impairments as compared with lesions of the posteromedial cortex. Only one of four rats with ablations of the dorsal bank and lip of the anterior part of the rhinal sulcus was impaired. The results indicate than in the rat, as in the monkey and dog, one part of the prefrontal cortex is particularly involved in mediation of delayed alternation.
\end{abstract}

A better understanding of the behavioral functions of the prefrontal cortex (PFC) depends, among other factors, on the possibility of dividing this area meaningfully into smaller units. Both in the monkey (Butters, Pandya, Sanders, \& Dye, 1971; Warren \& Divac, 1973) and the dog (Lawicka, Mishkin, Kreiner, \& Brutkowski, 1966; Lawicka, 1972), the cortical projection area of the mediodorsal thalamic nucleus (i.e., PFC) contains "focus" for delayed responsetype behavior. In the rat, it has been shown that PFC on the anteromedial surface of the hemisphere mediates delayed response-type behavior (Divac, 1971; Kolb, Nonneman, \& Singh, 1974; Wikmark, Divac, \& Weiss, 1973). It is not known, however, whether one subfield has a more decisive role than the remaining cortex in this area, or whether the suprarhinal part of PFC also participates in mediation of delayed alternation.

The present experiment was designed to answer these questions. The pregenual and supragenual areas of anteromedial cortex were separately ablated. These two fields have different dopaminergic innervation, Lindvall, Björklund, \& Divac, 1978; Lindvall, Björklund, Moore, \& Stenevi, 1974) and receive afferents from two separate portions of the mediodorsal thalamic nucleus (Divac, Kosmal, Björklund, \& Lindvall, 1976). A third group of animals received ablations of the anterior part of the dorsal bank and the lip of the rhinal sulcus which also receive afferents from the mediodorsal thalamic nucleus. The control group consisted of the rats with ablations of the posteromedial "limbic" cortex. This cortical area can be easily denervated by the more anterior medial lesions, since its connections pass around the genu of corpus collosum. (Domesick, 1969, 1970).

\section{METHOD}

\section{Animals}

Twenty-five "naive" male rats of Wistar strain were used in this study. They were individually housed, with water always available and food supplement given once a day after testing.

\section{Apparatus}

The corridor T-maze described in some earlier studies (Öberg \& Divac, 1975; Wikmark et al., 1973) was used in the present study.

\section{Procedure}

Our standard method of testing is described in detail elsewhere (Öberg \& Divac, 1975; Wikmark et al., 1973). Briefly, well-handled rats were shaped to run in a T-maze and then given 20 trials daily. Choice of the alley not visited on the preceding trial was rewarded by mashed rat chow, while choice of the same alley resulted in removal from the maze and prolonged waiting in a transfer cage. Each rat was trained until it made 6 errors or less in three successive sessions and not more than 3 errors on any of these days. After reaching this criterion, the rat waited for 10 days and was retested for preoperative retention during at least 3 days. The rat that was at the criterion level during this test was operated on the following day, left in the home cage for 10 days, and then tested for postoperative retention for 3 days (60 trials). Rats which needed retraining to criterion in the preoperative retention test waited for another block of 10 days and were then given a second preoperative retention test. Following criterion performance, the animal was operated on. The tester did not know until the end of experiment to which group an animal belonged.

\section{Surgery and Histology}

The ablations were made, under Equithesin $(3.3 \mathrm{ml} / \mathrm{kg})$ anaesthesia, by suction with the aid of an operating microscope. The border between the anteromedial and posteromedial areas was arbitrarily established at bregma. The anteromedial cortex was subdivided into two subfields by a vertical line passing through a point which bisected the distance between bregma and the tip of the hemisphere into equal halves.

At the end of the experiment, all animals were perfused in aneasthesia with saline followed by $10 \%$ Formalin. The brains were cut either into $100-\mu \mathrm{m}$ slices in a freezing microtome or into $30-\mu \mathrm{m}$ sections in a cryostat. The lesions were drawn by means of a microfilm reader.

\section{RESULTS}

The lesions are represented in Figures 1, 2, and 3. Overlap between the lesions was found only at the level A: 9650 between the pregenual and supragenual 


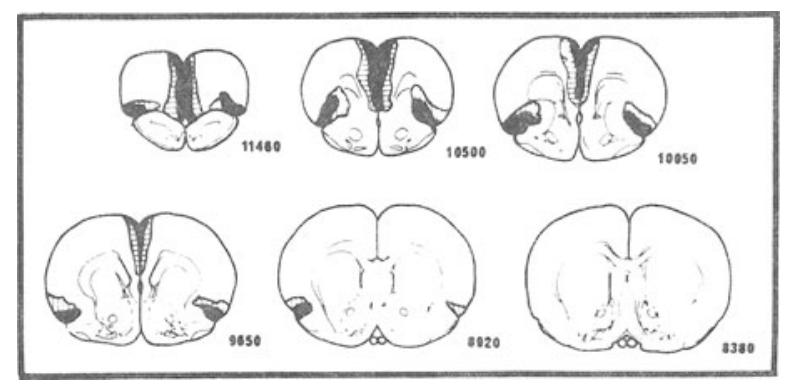

Figure 1. Schematic representation of the smallest (black) and the largest (stripes) lesion of the precallosal and suprarhinal cortex (drawn on the same set of sections).

groups, and at levels A: $6060-5150$ between the supragenual and posteromedial groups.

The strongest impairment of delayed alternation was produced by the pregenual lesions (Figure 3); the supragenual lesions caused some, but smaller, impairments. The difference between the two groups was statistically significant (Mann-Whitney, $\mathrm{p}<.05$ ). Ablation of the suprarhinal cortex impaired only one of four animals. All rats with posteromedial lesions performed at the criterion level at the first 60 postoperative trials. Since these lesions were very similar to the supragenual ablations, the illustration was unnecessary.

\section{DISCUSSION}

The present study indicates that one part of PFC in the rat is more involved in mediation of delayed response-type behavior than other prefrontal areas. Similar results have been obtained in rhesus monkeys
(Butters et al., 1971; Warren \& Divac, 1972) and dogs (Lawicka, 1972; Lawicka et al., 1966). In all three species, however, the functional specialization of the subdivisions of prefrontal cortex is not absolute: ablation of other prefrontal areas either produced a small impairment in delayed response-type behavior when made alone or enhanced the impairment obtained with removal of the "focal" region (Gross, 1963; Iversen \& Mishkin, 1970; Lawicka et al., 1966; Mishkin, Vest, Waxler, \& Rosvold, 1966; Stamm \& Weber-Levine, 1971). Studies on monkeys and dogs have shown that the relative importance of the nonfocal parts of the prefrontal cortex is higher in some individuals; the same phenomenon was apparent in the present study. This fact, as well as the equally puzzling absence of impairment of delayed alternation in some animals even with large prefrontal ablations (Divac, 1972; Wikmark et al., 1973), accounts for the necessity to increase the size of the groups in order to detect functional dissociation.

In the rat, the "focal" area for delayed alternation appears to be the pregenual cortex. The dorsal portion of this area receives projections from the lateral part of the mediodorsal thalamic nucleus (Divac et al., 1976; Krettek \& Price, 1977). Also in the monkey, the focus for delayed response-type behaviors lies within the projection field of the lateral portion of the mediodorsal nucleus (Butters et al., 1971; Warren \& Divac, 1972).

Impairments in "prefrontal tasks" after prefrontal ablations in different species are qualitatively similar (review in Wikmark et al., 1973), but the degree of impairment is much higher in the monkey (e.g., Divac \& Warren, 1971; Stamm, 1970) than in dogs (Lawicka,

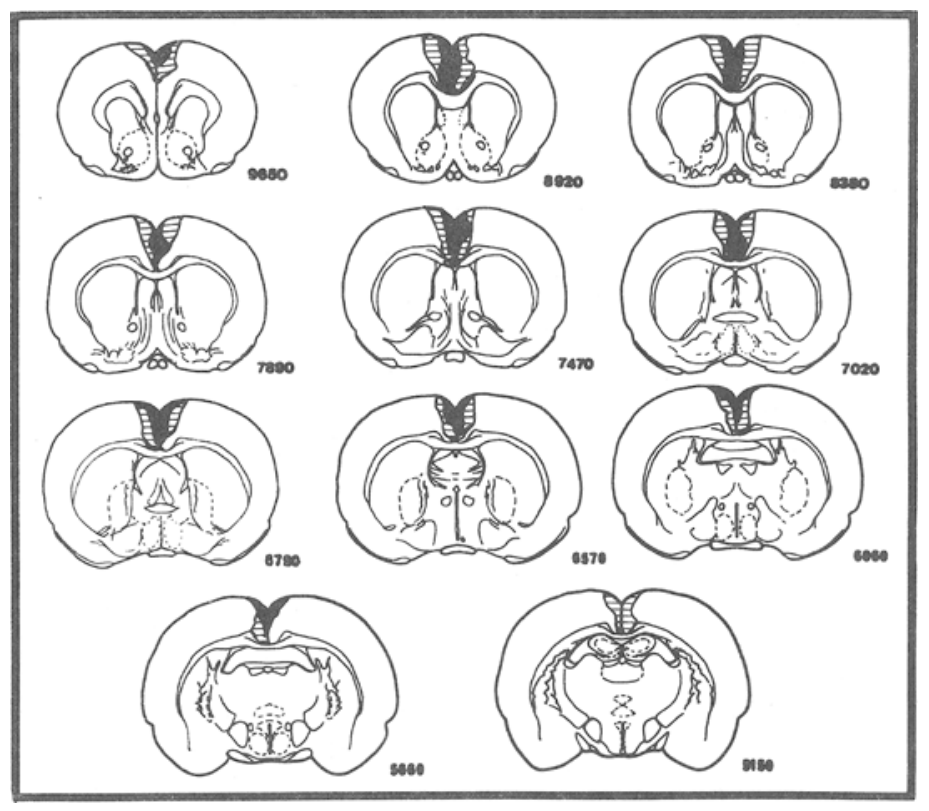

Figure 2. Schematic representation of the smallest (black) and the largest (stripes) lesion of the supragenual cortex. 


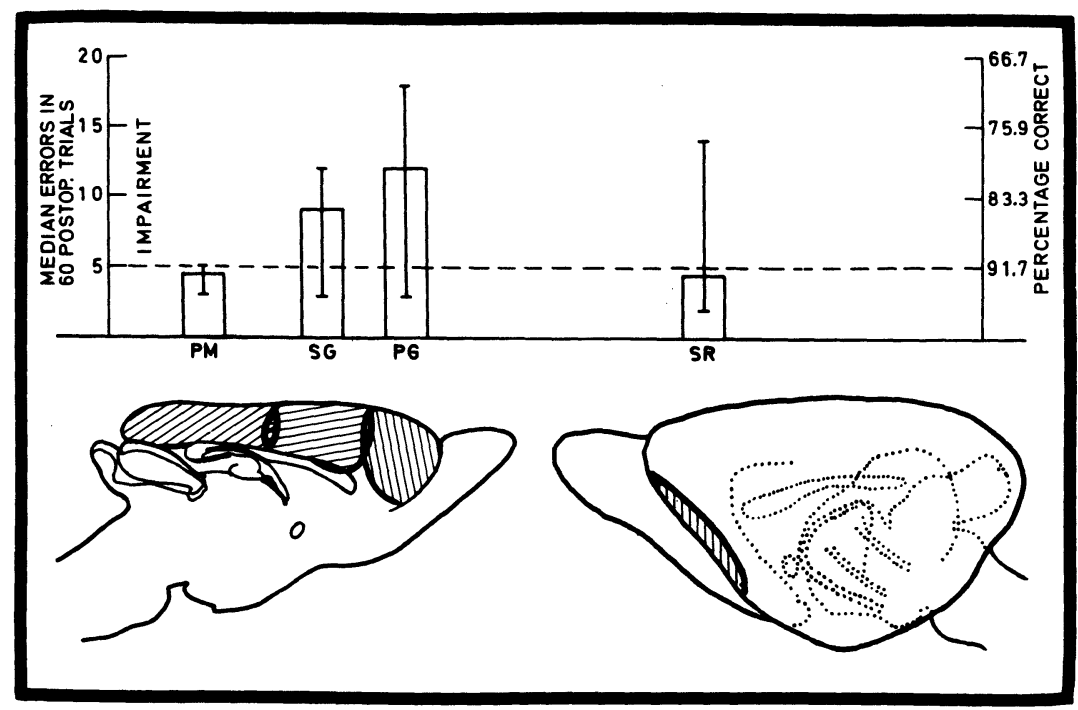

Figure 3. The results of the postoperative retention test for all groups. The histogram columns are drawn above the corresponding lesions. PM: $n=4$; SG: $n$ = 9; PG: $\mathrm{n}=8$; SR: $n=4$.

1969), cats (Divac, 1972), or rats (present data; Divac, 1971; Wikmark et al., 1973). No explanation for these species differences is available.

In conclusion, PFC in the rat shows, as it does in the dog and monkey, a regional specialization of function. Thus, in species from as different orders as rodents, carnivores, and primates, PFC not only mediates the same functions (see review in Wikmark et al., 1973), but appears to be functionally heterogeneous.

\section{REFERENCES}

Butters, N., Pandya, D., Sanders, K., \& Dye, P. Behavioral deficits in monkeys after selective lesions within the middle third of sulcus principalis. Journal of Comparative \& Physiological Psychology, 1971, 76, 8-14.

Divac, I. Frontal lobe system and spatial reversal in the rat. Neuropsychologia, 1971, 9, 175-183.

Divac, I. Delayed alternation in cats with lesions of the prefrontal cortex and the caudate nucleus. Physiology and Behavior, 1972, 8, 519-522.

Divac, I., Kosmal, A., Björkiund, A., \& Lindvall, 0. Subcortical projections to the frontal and medial cortex in the rat. Patterns of subcortico-cortical projections. Neuroscience Abstracts, 1976, 2 (Part I), 134.

Divac, I., \& WARREN, J. M. Delayed response by frontal monkeys in the Nencki testing situation. Neuropsychologia, 1971, 9, 209-217.

Domesick, V. B. Projections from the cingulate cortex in the rat brain. Brain Research, 1969, 13, 296-320.

Domesick, V. B. The fasciculus cinguli in the rat. Brain Research, 1970, 20, 19-32.

Gross, C. G. A comparison of the effects of partial and total lateral frontal lesions on test performance by monkeys. Journal of Comparative \& Physiological Psychology, 1963, 56, 41-47.

IVERSEN, S. D.. \& Mishin, M. Perseverative interference in monkeys following selective lesions of the inferior prefrontal convexity. Experimental Brain Research, 1970, 11, 376-386.

Kolb, B., Nonneman, A. J., \& Singh, R. K. Double dis- sociation of spatial impairments and perseveration following selective frontal lesions in rats. Journal of Comparative \& Physiological Psychology, 1974, 87, 772-780.

Krettek, J. E., \& Price, J. L. The cortical projections of the mediodorsal nucleus and adjacent thalamic nuclei in the rat. Journal of Comparative Neurology, 1977, 171, 157-191.

LAWICKA, W. A proposed mechanism for delayed response impairment in prefrontal animals. Acta Biologiae Experimentalis (Warsaw), 1969, 29, 401-414.

Lawicka, W. Proreal syndrome in dogs. Acta Neurobiologiae Experimentalis, 1972, 32, 261-276.

Lawicka, W., Mishkin, M., Kreiner, J., \& Brutkowski, S. Delayed response deficit in dogs after selective ablation of the proreal gyrus. Acta Biologiae Experimentalis (Warsaw), 1966, 26, 309-322.

Lindvall, O., Björkiund, A., \& Divac, I. Organization of catecholamine neurons projecting to the rat frontal cortex. Brain Research, in press.

Lindvall, O., Björkiund, A., Moore, R. Y., \& Stenevi, U. Mesencephalic dopamine neurons projecting to neocortex. Brain Research, 1974, 81, 325-331.

Mishinin, M., Vest, B., WAXler, M., \& Rosvold, H. E. A reexamination of the effects of frontal lesions on object alternation. Neuropsychologia, 1969, 7, 357-363.

ÖвERG, R. G. E., \& Divac, I. Dissociative effects of selective lesions in the caudate nucleus of cats and rats. Acta Neurobiologiae Experimentalis, 1975, 35, 647-659.

Stamm, J. S. Dorsolateral frontal ablations and response processes in monkeys. Journal of Comparative \& Physiological Psychology, 1970, 70, 437-447.

Stamm, J. S., \& Weber-Levine, M. L. Delayed alternation impairments following selective prefrontal cortical ablations in monkeys. Experimental Neurology, 1971, 33, 263-278.

WARREN, J. M., \& Divac, I. Delayed response performance by rhesus monkeys with midprincipalis lesions. Psychonomic Science, 1972, 28. 146-148.

Wikmark, R. G. E., Divac, I., \& Weiss, R. Retention of spatial delayed alternation in rats with lesions in the frontal lobes. Brain, Behavior \& Evolution, 1973, 8, 329-339.

(Received for publication September 7, 1977; accepted October 26, 1977.) 